\title{
Utilização de água residuária no crescimento de espécies arbóreas da Caatinga
}

\author{
Márcia Ellen Chagas Santos, Silvanete Severino da Silva, Cláudia Facini Reis
}

\begin{abstract}
RESUMO: O objetivo do presente trabalho foi avaliar o uso das águas residuárias no crescimento de espécies arbóreas da caatinga na recuperação de área degradada. O ensaio foi conduzido em condições de campo, em área de degradação agrícola e biológica, na sede do Instituto Nacional do Semiárido, em Campina Grande-PB. Foram testados três tratamentos, com dez repetições cada, seguindo um delineamento em blocos ao acaso, os quais foram distribuídos com: 0,5 litro de água de abastecimento; 1,0 litro de água de efluente doméstico tratado; e 0,5 litro de água de efluente doméstico tratado; todos por planta e para cada irrigação efetuada semanalmente, sendo associadas ao crescimento de espécies nativas da caatinga. Para análise do efeito dos tratamentos foram mensurados aos 216; 312; 346; 421; 514; 594; 724 e 871 dias após o transplantio e, posteriormente determinou-se a taxa de crescimento relativo para a altura de planta nas espécies Aroeira e Sabiá. Os resultados evidenciaram o favorecimento da água residuária sob o crescimento das espécies avaliadas. A irrigação com água residuária favorece a permanência das espécies em área degradada.
\end{abstract}

Palavras-chave: irrigação, efluente doméstico, sabiá, aroeira.

\section{Utilization of wastewater in the growth of Caatinga tree species}

\begin{abstract}
Soil use in shrub-tree crops of soybean crop is an arboreal growth of the caatinga in the recovery of degraded area. The experiment was carried out under field conditions, in an area of agricultural and biological degradation, at the headquarters of the National Semiarid Institute, Campina Grande-PB. Three treatments were tested, with ten replicates each, following a randomized block design, with which they were aligned with: 0.5 liter of water supply; 1.0 liter of effluent water treated at breakfast; and 0.5 liter of treated effluent water; All plants and for each irrigation carried out, while associated to the growth of native caatinga species. The analysis of the effects were measurable to $216 ; 312 ; 346 ; 421 ; 514 ; 594 ; 724$ and 871 days after transplantation and, later, the growth rates relative to a plant height in the Aroeira and Sabiá species were determined. The evidence of the evaluation of the made in the product status in the growth. Irrigation with wastewater favors the permanence of the species in a degraded area.
\end{abstract}

\section{INTRODUÇÃO}

O experimento foi conduzido entre 24 de julho de 2015 e julho de 2017, em condições de campo, na sede do Instituto Nacional do Semiárido (INSA), localizada no município de Campina Grande-PB. O local se encontra na região fisiográfica do Cariris Velhos com as coordenadas geográficas latitude $07^{\circ}$ $27^{\prime} \mathrm{S}$, longitude $35^{\circ} 95^{\prime} \mathrm{W}$ e altitude média de 550 $\mathrm{m}$, possuem clima quente e úmido com regime pluviométrico irregular e longo período de estiagem classificado como As' de acordo com a classificação de Köppen (1918). Nesse período a temperatura do ar varia entre a máxima anual de $30,5^{\circ} \mathrm{C}$ e a mínima de $20,5^{\circ} \mathrm{C}$, e a umidade relativa com média em torno de $80 \%$.

Foram testados três tratamentos, com dez repetições cada, seguindo um delineamento em blocos ao acaso, os quais foram assim denominados: Aplicação de 0,5 litro de água de abastecimento, por planta, em cada irrigação, aplicação de 1,0 litro de água de efluente doméstico tratado, por planta, em cada irrigação, aplicação de 0,5 litro de água de efluente doméstico tratado, por planta, em cada irrigação, que foram associadas ao crescimento de espécies nativas da caatinga.

A seleção consistiu na escolha da espécie Aroeira Branca (Astroium urundeuva - Allemão), e na espécie Sabiá (Mimosa ceasalpinifolea). Cada espécie arbórea foi distribuída como unidade experimental sendo composta por uma fileira de plantas de $20 \mathrm{~m}$ de comprimento por 2 metros de largura totalizando uma área de $40 \mathrm{~m}^{2}$, considerando as 30 unidades experimentais a área total do experimento foi de $1200 \mathrm{~m}^{2}$. As mudas foram plantadas em distância de 2 metros ao longo das fileiras com três plantas úteis, de cada espécie. No total foram transplantadas 240 mudas sendo 120 de Sabiá e 120 de Aroeira.

A água residuária utilizada foi proveniente da estação de tratamento secundária anaeróbica, localizada próxima à área experimental, a qual segue

\footnotetext{
Recebido em 05/10/2019, Aceito para publicação em 15/10/2019

${ }^{1}$ Universidade Federal Rural do Semi-Árido

2 Universidade Federal de Campina Grande

*e-mail: hellen_santos_a51@ @otmail.com
} 
o Manual de Saneamento - Orientações Técnicas (FUNASA, 2007), com tanque séptico - Primário; e filtro anaeróbio - Secundário.

A estação foi construída com o empenho de tanque séptico de câmara única, seguido de quatro unidades filtrantes anaeróbias. A água residuária tem origem doméstica, caracterizada de águas cinza e águas escuras, compondo toda água servida da sede do INSA, com capacidade para fluxo de até 48 pessoas dia $^{-1}$.

As amostras da água residuária aplicadas foram obtidas no tanque séptico, de tratamento primário, após os tratamentos e também diretamente no gotejador para fins de caracterização e verificação dos componentes físicos, químicos e microbiológicos, que foram coletadas nos reservatórios na altura intermediária da lâmina de água. A coleta foi realizada com material estéril, sempre no período matutino. Após a coleta as garrafas foram identificadas e imediatamente levadas ao laboratório da Universidade Federal de Campina Grande, denominado de Extrabes, e a análise foi realizada 24 horas após a coleta.

Quanto à água convencional, as análises físicoquímicas da água proveniente da Companhia de Água e Esgotos da Paraíba (CAGEPA), a qual é captada do Açude Epitácio Pessoa, localizado no município de Boqueirão, conforme a metodologia descrita para a água residuária. A coleta foi composta e retirada na torneira no gotejador.

A água foi distribuída por sistema de irrigação localizada através do método de gotejamento. As irrigações foram realizadas uma vez a cada semana, sendo distribuída em dois volumes controlados pelo tempo de 28 minutos quando irrigado 1 litro por planta, e 14 minutos quando irrigado 0,5 litros por planta.

Antes do plantio não foi realizado qualquer remoção de material, bem como a adição de material orgânico. A marcação e confecção das covas tiveram as dimensões de $20 \times 20 \times 20 \mathrm{~cm}$, o espaçamento usado para o plantio. As covas para não receberam acréscimo de adubação, foram preenchidas totalmente pelo solo que foi retirado antes do plantio das mudas.

Os tratos culturais foram realizados por campinas manuais, sempre preservando o material coletado na própria área. As plantas passaram por tutoramento quando seu crescimento vertical excedeu os $40 \mathrm{~cm}$.

Para análise do efeito dos tratamentos sobre o crescimento de espécies nativas da caatinga, foram mensurados aos 216; 312; 346; 421; 514; 594; 724 e 871 dias após o transplantio (DAT) e, posteriormente determinou-se a taxa de crescimento relativo (TCRAP) para a altura de planta (AP) nas espécies Aroeira e Sabiá.

O período de avaliação foi escolhido em função da análise inicial dessas plantas, estando elas acima da altura de $30 \mathrm{~cm}$, bem como, pelo acrescimento de dois anos de água residuária nessa área degradada. A TCRAP foi determinada de acordo com metodologia descrita por Benincasa (2003), conforme Equação 1. As amostras foram sucessivas, a pelo menos 60 dias.

$$
T C R=\frac{\left(\ln A P_{2}-\ln A P_{1}\right.}{\left(T_{2}-T_{1}\right)} \quad(\text { Equação } 1)
$$

Em que: TCR $=$ taxa de crescimento relativo em altura de planta $\left(\mathrm{cm} \mathrm{cm}^{-1}\right.$ dia $\left.^{-1}\right) ; \mathrm{Ln}=$ logaritmo natural; $\mathrm{AP} 2=$ altura de planta final, $\mathrm{cm}$; AP1 = altura de planta inicial, $\mathrm{cm} ; \mathrm{T} 2$ = tempo final, dias; $\mathrm{eT} 1=$ tempo inicial, dias.

Os dados obtidos foram avaliados mediante análise de variância pelo teste ' $F$ ' ao nível de 0,05 e 0,01 de probabilidade utilizando o software estatístico SISVAR-ESAL (Lavras, MG) (FERREIRA, 2014).

\section{RESULTADOS E DISCUSSÃO}

Observa-se na Tabela 4 que não houve efeito significativo do fator Ano (A) sobre o taxa de crescimento relativo da altura de plantas (TCRAT), no crescimento da Aroeira e Sabiá nos dois últimos períodos para a Sabiá. Ressalta-se que não é feito análise comparativa entre as espécie, mas sim, explicado o comportamento de cada uma e de acordo com o seu desempenho conforme a literatura.

Tabela 1. Teste F para a taxa de crescimento relativo da altura de planta (AP) de espécies nativas da caatinga no período de 216 ; 312; 346; 421; 514; 594; 724 e 871 dias após o transplantio (DAT) em função de lâminas de irrigação com água residuária em dois diferentes anos

\begin{tabular}{|c|c|c|c|c|c|c|c|c|c|}
\hline \multirow{4}{*}{ FV } & \multirow{4}{*}{ GL } & \multicolumn{8}{|c|}{ Quadrados médios } \\
\hline & & \multicolumn{8}{|c|}{ Espécies Nativas } \\
\hline & & \multicolumn{4}{|c|}{ Aroeira } & \multicolumn{4}{|c|}{ Sabiá } \\
\hline & & $\mathbf{T x}_{1}(\%)$ & $\mathbf{T x}_{2}(\%)$ & $\mathrm{Tx}_{\mathbf{3}}(\%)$ & $\mathbf{T x}_{4}(\%)$ & $\mathrm{Tx}_{1}(\%)$ & $\mathbf{T x}_{2}(\%)$ & $\mathbf{T x}_{\mathbf{3}}(\%)$ & $\mathrm{Tx}_{4}(\%)$ \\
\hline Ano (A) & 1 & $0,84^{\mathrm{ns}}$ & $108,26^{\mathrm{ns}}$ & $4,87^{\mathrm{ns}}$ & $6,35^{\mathrm{ns}}$ & $262,85^{\mathrm{ns}}$ & $161,07^{\mathrm{ns}}$ & $0,07^{\mathrm{ns}}$ & $0,73^{\mathrm{ns}}$ \\
\hline Trat (T) & 2 & $0,78^{\mathrm{ns}}$ & $7,83^{\mathrm{ns}}$ & $1,85^{\mathrm{ns}}$ & $1,07^{\mathrm{ns}}$ & $22,32^{\mathrm{ns}}$ & $10,01^{\mathrm{ns}}$ & $1,67^{\mathrm{ns}}$ & $1,00^{\mathrm{ns}}$ \\
\hline AxT & 2 & $2,98^{\mathrm{ns}}$ & $55,75^{\mathrm{ns}}$ & $39,24^{\mathrm{ns}}$ & $2,81^{\mathrm{ns}}$ & $84,98^{* * *}$ & $0,03^{\mathrm{ns}}$ & $0,38^{\text {ns }}$ & $7,06^{\mathrm{ns}}$ \\
\hline BLO & 9 & $1,09^{\mathrm{ns}}$ & $12.08^{\mathrm{ns}}$ & $1,93^{\mathrm{ns}}$ & $1,35^{\mathrm{ns}}$ & $2,62^{\mathrm{ns}}$ & $12,75^{\mathrm{ns}}$ & $0,60^{\mathrm{ns}}$ & $1,32^{\text {ns }}$ \\
\hline Resíduo & 45 & 1,13 & 10,18 & 1,81 & 1,16 & 10,66 & 11,34 & 0,87 & 1,54 \\
\hline CV (\%) & & 22,07 & 26,69 & 21,12 & 21,60 & 21,93 & 26,02 & 24,55 & 26,70 \\
\hline
\end{tabular}

Em que: ${ }^{\text {ns }}$ não significativo pelo Teste F; Análise estatística realizada após transformação de dados em $\sqrt{ } \mathrm{x}$. 
Quanto ao efeito isolado dos tratamentos (lâminas de irrigação com água residuária), observase que não houve efeito significativo para nenhuma das espécies arbóreas. Em relação à interação entre os fatores (lâmina irrigada com água residuária para os dois anos para as espécies nativas). De fato, as espécies estão em condições de sobrevivência, já que a lâmina aplicada é mínima e solo não apresenta condições favoráveis.

Segundo Benincasa (1988), a taxa de crescimento relativo (TCR), representa a rapidez com que a planta cresce quando comparada com o seu tamanho inicial. Em campo, observa-se maior desenvolvimento para a espécie Aroeira, a partir dos seis primeiros meses, cuja principal característica é o crescimento acelerado e porte pequeno (MAIA, 2012). Fica evidente que o crescimento dessa planta após o primeiro ano (2016), chegando a quase $2 \%$ quando comparado na mesma época e com um ano de avaliação (2017). Ressalta-se que as médias de crescimento estão em conformidade com o período chuvoso.

Á respeito da espécie Sabiá, a maior taxa foi durante o início do experimento, com ganhos de até 2,2\% nos meses avaliados. A espécie Sabiá possui elevado desenvolvimento em áreas degradadas, especialmente, em locais onde tenha ocorrido exibição do subsolo, sendo pouco rigorosa em fertilidade e umidade do solo (CARVALHO, 2007). Conforme Silva et al. (2010), o Sabiá pode possibilitar melhoramento da estrutura do solo, assim como absorver matéria orgânica ao solo e presta-se a cobertura vegetal.

$O$ não êxito total da espécie Sabiá estatisticamente pode está aliado a mortandade, correspondente a $14,2 \%$ do total, justificando dessa forma, a redução da taxa de crescimento. A espécie de Aroeira, sofreu mortandade mínima, de apenas 2,5\% do total.

Em geral, o comportamento de crescimento maior foi da Aroeira quando adicionado o volume de 0,5 litros de água residuária e 0,5 litros de água convencional para o ano de 2016. Isso pode ser explicado na aplicação da água, bem como, na interação com as maiores chuvas da época.

Por outra forma, Brito et al. (2016), estudando o crescimento da Aroeira irrigado com esgoto doméstico condicionaram o desenvolvimento da espécie ao solo com o esterco bovino para todos os tratamentos, independentemente da solução nutritiva da irrigação. Contudo, toda a área apresenta baixa profundidade, alta exposição solar, além da intensa pedregosidade, dificultando o desenvolvimento radicular das plantas.

\section{CONCLUSÃO}

Resultados de crescimento e desenvolvimento de espécies nativas da caatinga irrigadas com água residuária, são obtidos em longo prazo, após a fase de adaptação e fixação das espécies em área degradada.

A espécie aroeira apresentou melhor desempenho quanto ao seu crescimento para o primeiro ano.

A espécie sabiá apresentou comportamento crescente ao longo das fases avaliadas.

\section{REFERÊNCIAS}

AUGUSTO, D. C. C., GUERRINI, I. A., ENGEL, V. L., \& ROUSSEAU, G. X. Utilização de águas residuárias provenientes do tratamento biológico de esgotos domésticos na produção de mudas de Eucalyptus grandis Hill. Ex. Maiden. Revista Árvore, 745-751, 2007.

ALBURQUERQUE, F. A. de. Ocorrência do Manémagro (Orthoptera: Proscoplidae) em plantas de Pinhão Manso no Sertão Paraibano. Comunicado Técnico 367. Campina Grande-PB, 2009.

BENINCASA, M. M. P. Análise de crescimento de planta, noções básicas. Jaboticabal: FUNEP, 1988. 41p.

BENINCASA, M. M. P. Análise de crescimento de plantas, noções básicas. 2. ed. Jaboticabal: FUNEP, p.41, 2003.

BEZERRA, B. G.; FIDELES FILHO, J. Análise de crescimento da cultura do algodoeiro irrigada com águas residuárias. Revista Ciência Agronômica, v. 40, n. 3, p. 339-345, 2009.

BRITO, R. F. de; FERREIRA NETO, M.; LIRA, R. B.; ALMEIDA, K. L. de; COSTA, J. P. N. da; DIAS, N. da S. Crescimento de aroeira irrigado com esgoto doméstico tratado. II Workshop de Manejo de Água de Qualidade Inferior. Mossoró-RN, 2016,

CARVALHO, P. E. R. Sabiá (Mimosa caesalpiniifolia). Colombo: Embrapa Floresta, 2007. 10p. (Circular Técnica, 135).

DONAGEMA, G. K. Manual de métodos de análises de solos. 2. ed. Rio de Janeiro: Embrapa Solos, 2011. 230p.

FERREIRA, D. F. Sisvar: a Guide for its Bootstrap procedures in multiple comparisons. Ciênc. Agrotec. v.38, n.2, p.109-112, 2014.

FUNASA. Fundação Nacional de Saúde. Aplicação controlada de água residuária e lodo de esgoto no solo, para melhorar e incrementar a agricultura do semiárido nordestino. Brasília, DF, 2007. 120p.

INSA. Instituto Nacional do Semiárido. Relatório popularizado 2014. Pela convivência, resiliência e resistência: Construindo juntos estratégias na Ciência, Tecnologia e Inovação que se alimentam mutuamente. 
2014.

https://portal.insa.gov.br/images/acervo-

relatorios/Relat\%C3\%B3rio\%20Popularizado\%202014.p

df. Acesso em: 20 de março de 2018.

KÖEPPEN, W. Klassification der klimate nach temperatura, niederschlag und jahreslauf. Pet. Geo. Mitt. Gotha, v.64, p.193-203, 1918.

KOHL, K. D. Mechanics of rill head cutting. Retro. Theses Dissertations, 8861, 1988.

LORENZI, H. Árvores Brasileiras: Manual de identificação e cultivo de plantas arbóreas nativas do Brasil. 5. ed., v.1, Nova Odessa, SP: Instituto Plantarum, 2008. 384p.

MAIA, G. N. Caatinga: árvores e arbustos e suas utilidades. 2. ed. Fortaleza: Printcolor Gráfica e Editora, 2012. 413p.

MUYEN, Z.; MOORE, G. A.; WRIGLEY, R. J. Soil salinity and sodicity effects of wastewater irrigation in South East Australia. Agricultural Water Management, v.99, n.1, p.33-41, 2011. em: PEREIRA B. F. F.; HE, Z. L.; STOFFELLA, P. J.; MELFI, A. J. reclaimed wastewater: effects on citrus nutrition. Agricultural Water Management, v.98, n.12, p.1828-1833, 2011.

QUEIROZ, L. P. Leguminosas da Caatinga. Feira de Santana: Universidade Estadual de Feira de Santana, 1. ed., 2009. 443p.

SILVA, R. B. L. Diversidade, uso e manejo de quintais agroflorestais no Distrito do Carvão, Mazagão-AP, Brasil. Tese (Doutorado). Núcleo de Altos Estudos Amazônicos, Programa de Pós-Graduação em Desenvolvimento Sustentável do Trópico Úmido. Universidade Federal do Pará. Belém, 2010.

VEDACHALAM, S.; MANCL, M. K. Water resources and wastewater reuse: perception of students at Ohio State University campus. Ohio Journal of Science, v.110, n.5, p.104-113, 2012. 